\title{
Job Performance and Job Satisfaction: Roles of Organizational Commitment and Psychological Contract
}

\author{
Cheng-Wei Che ${ }^{1}$, Pei-Ling Tsui ${ }^{2}$, Ming-Chih Chen ${ }^{1}$, Ching-Sung Lee ${ }^{3}$, Yen-Cheng Chen ${ }^{4 *}$ \\ ${ }^{I}$ Graduate Institute of Business Administration, Fu Jen Catholic University, Taiwan \\ ${ }^{2}$ Department of Hospitality Management, National Taitung College, Taiwan \\ ${ }^{3}$ Department of Restaurant, Hotel and Institutional Management, Fu Jen Catholic University, Taiwan \\ ${ }^{4 *}$ Department of Applied Science of Living, Chinese Culture University, Taiwan
}

*Corresponding Author: Yen-Cheng Chen, Department of Applied Science of Living, Chinese Cultural University, Taiwan

\begin{abstract}
This study empirically examined the relationship between job satisfaction and job performance of employees through the mediating effect of psychological contract and organizational commitment in the context of hospitality. Specifically, this study applied regression and Sobel test technique to identify these effects. The results of the analysis confirmed the relationships between our proposed variables. This result suggests that job satisfaction is a key factor in our explanatory model of job performance, in which job satisfaction generates positive effect and passes it onto job performance directly and indirectly. Psychological contract and organizational commitment are important mediators in the relationships between job performance and job satisfaction.
\end{abstract}

Keywords: Job satisfaction, job performance, mediator, psychological contract, organizational commitment.

\section{INTRODUCTION}

Satisfaction is considered a critical factor of performance in organizational behavior studies. Researchers suggest that high levels of job satisfaction have positive impact on overall organizational performance. Although the connections between job satisfaction and job performance seem instinctive, relative few studies support them empirically (Iaffaldano\&Muchinsky, 1985). On the other hand, job dissatisfaction usually leads to negative behaviors e.g. absence, quitting and negligence, hence the negative impact to organizations (Bakker, Demerouti, \&Sanz-Vergel, 2014; Homet al., 1992; Organ, 1988; Steers \& Rhodes, 1978; Rusbultet al., 1982).

Job dissatisfaction discussed in this study does not focus on only the dissatisfaction of job itself, but includes five dimensions: job itself, payment, promotion, supervisor and coworker. Researchers showed that most job dissatisfaction were due to dissatisfaction to work environment. Dissatisfied employees have four possible reactions: 1 . Leave the organization and find another job; 2 . Stay and try to improve the situation; 3. Stay but grow passive and less expectation (Farrell,1983; Halbesleben et al., 2014; Hagedoornet al., 1999; Rusbultet al., 1983; Wthey\& Cooper,1992 ,1999). Zhou and George (2001) suggested that opinions and advices from dissatisfied employees are important to organizations. Job dissatisfaction has potential positive effect on organizational performance (March \& Simon, 1958; Staw, 1984; Zhou \& George, 2001).

Organization commitment is the attitude or psychological tendencies of an individual to recognize an organization (Mowdayet al., 1982). Organization commitment is a predictor of resignation behavior and work performance, and also an effective measurement of organization performance (Morris \& Sherman, 1981; Ferries \&Aranya, 1983;Dawson, Karahanna, \&Buchholtz, 2014;Solinger et al., 2016). Therefore, organization commitment receives high respect from researchers and mangers, and regarded as an importance factor to improving organization performance. Organization commitment is classified into three dimensions: affective, continuance and normative (Meyer \& Allen, 1997). Among these three dimensions, continuance commitment measures one's cost elements when leaving an organization. Members will calculate the opportunities of external job offerings and perceived costs and sacrifices to leave current organizations. Continuance commitment was a key factor in Meyer and 
Allen (1991), in which the antecedents (e.g. personal characteristics and work experiences) and the consequences (e.g. work performance) were also discussed.

This study applied psychological contract which describing the concept framework with directly measuring the underlying psychological mechanisms. We emphasized the reciprocal relationships between employees and organizations (Sandral\& Elizabeth, 1995). Morrison (1994) believed that psychological contract is a predictive variable of current and future employee performances. High levels of psychological contract are beneficial for fostering trust and bring high levels of loyalty. On the contrary, violated psychological contract causes lower levels of organization commitment, worse work and job performance and resignations (Granter et al., 2015; Robinson \& Morrison, 1995; Turnley\& Feldman, 1999). This study focused on the effect of job dissatisfaction on continuance commitment, and the effect of continuance commitment on job performance. Further, do dissatisfied employees have higher levels of continuance commitment due to the moderating effect of psychological contract? These effects to final job performance were discussed in this paper.

\section{LiteratURE REVIEW}

\subsection{Job Satisfaction}

Hoppock (1935) posed the concept of job satisfaction. Job satisfaction is employees' degrees of satisfaction perceived in both physical and mental environmental factors. Job satisfaction is also regarded as the emotional orientations of employees' work roles. Positive attitudes represent the emotional orientations of job satisfaction; otherwise, it is the emotional orientations of job dissatisfaction (Vroom, 1964). Smith et al. (1969) deemed job satisfaction as an individual defining whether a job is good or bad and transform it into degrees of job satisfaction by comparing it to other individuals' jobs, abilities, experiences and job characteristics. Therefore, job satisfaction is an individual's overall feeling of reaction in the working environment of an organization. The feelings of happiness indicate the impressions of job satisfaction; otherwise, they express the impressions of job dissatisfaction.

We summarized some widely recognized factors affecting job satisfaction in the following sections. The two factor theory proposed by Herzberg (1968) explained that factors affecting job satisfaction can be separated into internal and external factors. Internal motivation factor includes variables related to job and work itself; external hygiene factor consists of interpersonal relations, work environments, organizational policies and payments. The result of Locke (1973) indicated that there are two types of factor influencing job satisfaction. The first type is the work event, involving work itself, work payment and work environment. The second type relates to people, including workers and individuals from inside and outside of the organizations. Job satisfaction was thought as the result of the interactions between first and second types of factors. Seashore and Taber (1975) distinguished factors affecting job satisfaction as personal factors and environmental factors. Personal factors incorporate variables such as personalities, abilities, perceptions and expectations. Environmental factors stand for political environments, economical environments, organizational environments and work environments.

In some particular behaviors of employees, Porter and Steer (1973) found that low degrees of job satisfaction worsen employees' absent rate and workload. In a research about nurses' job satisfaction, Price and Mueller (1981) revealed that high degree of job satisfaction was related to high retention, and resignations were less likely to happen. These results suggest that job satisfaction and job dissatisfaction are the two sides of the same coin.

\subsection{Job Satisfaction and Organizational Commitment}

When the organization to create an attractive environment, employees feel a part of them as belonging to the organization so it has their behavior choices. According to Mowday et al. (1982) organizational commitment is the relative strength of the individuals of a particular organization identification and involvement. Continuance commitment was derived from the exchange theory of Becker (1960). The focus of the theory is that members will evaluate according to their contributions to organizations and compensations from the organization to produce organizational commitment. If the exchange process was to their advantage, it will result in higher commitment to the organization, and vice versa to lower commitment. Morrow (1983) pointed out that the individual's attitude will further affect the degree of contribution to the organization. When a person has strong belief in the organization's goals and 
values, he/she is willing to strive for the organization's best interests, and hopes to become a part of the organization. This is the concept of continuance commitment to work.

Allen and Meyer (1996) defined commitment as: (1) affective commitment as the emotional attachment to the organization; (2) continuance commitment as the cognitive cost of leaving the organization; (3) normative commitment is considered the obligation to remain within the organization. Organizational commitment of their employees, while not based on emotional attachment (affective attachment) and alignments with the values and goals of the organization, but because of the need / necessity, this type of commitment is called continuance commitment (Meyer \& Allen, 1997). This study aims to understand that whether employees work in an organization who are not satisfied with the case are still willing to continuously contribute to the organization in any degrees. Therefore, organizations and task accomplishment are irrelevant (Bakker, Demerouti, \&SanzVergel, 2014; Meyer \& Allen, 1997). Under the circumstances of job dissatisfaction and to remain in the organizations due to the switching cost of works and continuance commitment, we obtained the first and second hypothesis:

H1: Job satisfaction has significant positive effect on organizational commitment.

H2: Organizational commitment has significant positive effect on job performance

\subsection{Psychological Contract}

Contract is an essential element in employment relationships. Contracts provide necessary constraints on behaviors between employees and organizations, and help organizations to achieve goals (Robinson et al., 1994). The psychological contract is a special form of contract. "Psychological contract" by Schein (1985), means for every member, managers and individuals, at any given time, there is a kind of expectations that does not explicitly exist. The psychological contract consists of two parts. First is the alignment of the individual employee's goals with organizational goals and commitments; Second, the emotional contract relationships that materialized into employees' dependency and loyalties for organizations after a series of contributions, reciprocal cycles and organizational experiences. Rousseau (1989) defined psychological contract as a person's belief in the reciprocal relationships of the issues and agreed to exchange the agreement for reciprocity with the other; as the expectations and beliefs of the receiving party's commitments of future compensations (such as bonus, promotion), that he/she will strive to make contributions (e.g. job performance). The formation of the obligation of the other side that should provide some benefits was termed psychological contract.

The psychological contract can be divided into: "transactional contract" and "relational contract" (MacNeil, 1985). Rousseau and Park (1993) deemed that "transactional contract" is highly specific, restrictively constrained, time to a lesser extent, and both sides of the transaction maintain great flexibility to reconfigure the contract, or to replace trading partners. In such short magnitude of time, inputs dedicate to transactions for the exchange relationship, such as special assets, organizationspecific skills, emotional investment and loyalty are quite limited. On the contrary, "relational contract" has no clear time limit and a wide range of specifications. Apart from financial resources, relational contract also consists of emotional factors and subjectivity (MacNeil, 1985); Relational contract is different to transactional contract, which mainly depends on the rules or provisions to regulate the parties to the transaction behavior.

Schein (1985) found that three psychological contract dimensions between employees and employers, which are: the general reciprocity that emphasizes altruistic and selfless; balanced reciprocity tends to be in the middle; negative reciprocity that request equal quality of reward, or a tooth for a tooth payback. Chinese scholars (Wu et al., 2006) who pursued accurate social norms in social exchange conducted three surveys to confirm Schein's scale. The company staff participated in the surveys confirmed three dimensions of psychological contract with high degrees of validity and reliability: altruistic general reciprocity (GR), medium balanced reciprocity (BR) and equal reward for the negative reciprocity (NR).

By the theoretical connotations that the psychological contract is the implicit contract between employees and enterprises, the key factor is employee satisfaction. High levels of organizational commitment improve employee satisfaction, promote and maintain the relationship between employees and enterprises. Therefore, psychological contract perspective has profound impact on the relationship between employees and organizations. Every employee believes that organizations can 
achieve their expectations, and fully devoted to the development of enterprises. Accordingly, the psychological contract emphasizes the mutually beneficial relationship between the employees in the organization (Sandral\&Elizabeth, 1995); Morrison (1994) argued that psychological contract is a predictor of employees' present or future work and provides a good grasp of work performance. It helps to develop better employees' trust and loyalty. On the other hand, the research pointed out that when the psychological contract is violated, the staff will result in lower organizational commitment, poor performance and poor job performance or resignation (Robinson and Morrison, 1995; Turnley\&Feldman, 1999; Solinger et al., 2016). Dissatisfied conditions encountered in the work environment due to the conflict between supervisors, inferior relationships with colleagues or uneven distribution of workload will affect the behaviors afterwards. However, does higher level of psychological contract serve as a moderator and mitigate the impact to continuance commitment when employees in the conditions of job dissatisfaction, therefore the third and fourth hypothesis:

H3: Job satisfactionhas significant positive effect on psychological contract.

H4: Psychological contract has significant positive effect on job performance.

\subsection{Job Performance}

According to Cascio (2006), managers must have an objective and impartial definition for performance that can be understood and accepted by the team and members, who will then fulfill the organizational expectations and reach organizational goals. Therefore, managers must set clear goals, and keep track of the target to achieve the process level, as well as to assess team or the performance of employees. While Byars and Rue (2000) considered performance as the reached process level of employees work in various tasks. Their definition for job performance of employees is the amendment efforts among their capabilities, roles or missions. Performance is the result of interactions among efforts, capabilities and role cognitions. Campbell $(1983,1990)$ deemed job performance of staff as the behavior of the completion of organizational expectations, complying with regulation or fulfilling role demand. Accordingly, job performance is the degree of employees assisting organizations to achieve their goals. Borman and Motowidlo (1993) highlighted that the job performance is individual behaviors related with organizational goals, and these individual behaviors can be measured by the attainment of contribution degree to the targets. Schermerhorn (1992) explained that job performance refers to the quality and quantity of tasks the individuals or groups have achieved.

The research of Brouthers (2002) explored situation, culture, and switching costs on entry mode choice and their impact on job performance, in which job performance is the degree of fulfillment to various tasks that individuals are responsible for to their positions. Job performance reflects employees' status of completing tasks and attainment to work demand. Brouthers categorized job performance into two dimensions: task performance and contextual performance. Kreitner and Kinicki (2001) proposed three methods to measure performance: trait-oriented, behavior-oriented and resultoriented performance. Dessler (2001) offered to measure job performance by six dimensions: job quality, productivity, job knowledge, reliability and effective level and independence. Dessler also suggested that supervisors, peers and employees themselves should evaluate job performance. Cascio (2006) developed the 360-degree feedback or multi-assessment performance evaluation method. This method provided extensive comparisons of self-recognized performance from diversified perspectives of supervisors, subordinates, colleagues and customers. Meyer and Allen (1997) put analogy between continuance commitment and cognitive cost of leaving the organization. Because members will take job offering opportunities and perceived cost and sacrifices into considerations, therefore continuance commitment have positive effect on employees to make them stay in the organizations and maintain performance. We then address our fifth and sixth hypothesis as:

H5: Job satisfaction has significant indirect effect on job performance through organizational commitment

H6: Job satisfaction has significant indirect effect on job performance through psychological contract.

\section{Methods AND Measurements}

\subsection{Sampling and Process}

The questionnaire was designed to testify the hypotheses proposed in the literature review and in order to understand the status of each variable. Sample in this study was drawn from chain restaurants employees and managers with stratified sampling. Staff members were asked to answer their personal information, job dissatisfaction, psychological contract and continuance commitment in the 
questionnaire; managers were asked to answer job performance of the staff members. Pretest was completed before the formal distribution of the questionnaire. Subjects of the pretest were university students in hospitality management related major who had current working experience in restaurants. Academic experts and scholars, as well as senior managers of the restaurant industry then reviewed the content of the questionnaire to ensure validity and reliability. Of totally 144 effective copies of questionnaires were recovered with a recovery rate of $100 \%$.

\subsection{Operational Definitions}

Refers to employees may be satisfied with the status of their own work also includes the unsatisfactory conditions of work environment factors. In this study, job satisfaction is a subjective feeling. We used employees' overall work-related factors to measure the degree of satisfaction (Moorman, 1991). Satisfaction and dissatisfaction represented a continuous band, in which lower level of dissatisfaction is analogue to high level of satisfaction. In this study, we followed Vitell and Davis (1990), Cellucci and DeVries (1978) theory to develop five dimensions scale of job satisfaction. The five dimensions include payment, promotion, colleagues, supervisors, and work itself. Each item was measured with a five-point likert scale, from one point very dissatisfied to very satisfied with five points. The lower the score indicated higher level of dissatisfaction; the higher the score favors higher level of satisfaction.

We adopted continuance commitment scale of Allen and Meyer (1996) to measure the staff's continuance commitment with six items and five-point likert scales, from a point strongly disagree to 5 points in full compliance with.

Reference to definition of Schein (1985): the psychological contract is the expectation of every member, manager and other individuals at any moment without express provision. According to the results of $\mathrm{Wu}$ (2006) which validated three dimensions developed by Schein (1985), the psychological contract questionnaire has considerable validity, and is generally applied in the different industries in major areas of mainland China. The psychological contract scales were composed of general reciprocity, balanced reciprocity and negative reciprocity, totally three dimensions with five-point Likert scale, from strongly disagree to strongly agree.

Job performance scale developed by Anget al. (2003), aimed to provide an assessment tool for managers to assess the employees' performance of the month. The measurement used five-point likert scale from strongly disagree to strongly agree.

\section{EMPIRICAL ANALYSIS}

We conducted Sobel test to examine the mediation effect by following a two-step regression procedure to compute the indirect effect of independent variable job satisfaction to dependent variable job performance. Table 1 is the test result of the mediating effect of organizational commitment. Model 1 is a regression analysis between job satisfaction and organizational commitment, which returns R-square of 0.813 and significance p-value less than 0.001 . Model 2 is a multiple regression with job performance as dependent variable, organizational commitment and job satisfaction as independent variables. This model has R-square of 0.558 and significant level p-value less than 0.001 . Because both models are significant, we then proceed to compute the indirect effect of job satisfaction on job performance. Sobel test returns an indirect effect of 0.325 with significant level p-value of 0.001 . Therefore, we conclude hypotheses $\mathrm{H} 1, \mathrm{H} 2$ and $\mathrm{H} 5$ are supported.

Table1. Sobel test result of the mediator organizational commitment

\begin{tabular}{|c|c|c|c|c|}
\hline \multicolumn{5}{|c|}{ Model 1 (D.V.=OrgComm) } \\
\hline$R^{2}$ & $F$-value & $\mathrm{df1}$ & $\mathrm{df2}$ & $p$-value \\
\hline 0.813 & 618.418 & 1 & 142 & $p$-001 \\
\hline I.V. & $B$ & $S . E$. & $t$ & $<0.001$ \\
\hline JobSatisf & 1.088 & 0.044 & 24.868 & $p$-value \\
\hline \multicolumn{4}{|c|}{ Model 2 (D.V.=Perform) } \\
\hline$R^{2}$ & $F$-value & $\mathrm{df1}$ & $\mathrm{df2}$ & $<0.001$ \\
\hline 0.558 & 88.905 & 2 & 141 & $p$-value \\
\hline I.V. & $B$ & $S . E$. & $t$ & 0.002 \\
\hline OrgComm & 0.299 & 0.093 & 3.219 & 0.008 \\
\hline JobSatisf & 0.301 & 0.112 & 2.689 & $p$-value \\
\hline Sobel Test & Indirect effect & $S . E$. & $Z$-value & 0.001 \\
\hline
\end{tabular}


Table2. Sobel test result of the mediator psychological contract

\begin{tabular}{|c|c|c|c|c|}
\hline \multicolumn{5}{|c|}{ Model 3 (D.V.=PsyCont) } \\
\hline$R^{2}$ & $F$-value & $\mathrm{df1}$ & $\mathrm{df2}$ & $p$-value \\
\hline 0.493 & 138.049 & 1 & 142 & $<0.001$ \\
\hline I.V. & $B$ & $S . E$. & $t$ & $<$-value \\
\hline JobSatisf & 0.885 & 0.075 & 11.749 & $<0.001$ \\
\hline \multicolumn{5}{|c|}{ Model 4 (D.V.=Perform) } \\
\hline$R^{2}$ & $F$-value & $\mathrm{df1}$ & $\mathrm{df2}$ & $p$-value \\
\hline 0.592 & 102.430 & 2 & 141 & $<0.001$ \\
\hline I.V. & $B$ & $S . E$. & $t$ & $p$-value \\
\hline PsyCont & 0.249 & 0.052 & 4.817 & $<0.001$ \\
\hline JobSatisf & 0.406 & 0.065 & 6.216 & $<0.001$ \\
\hline Sobel Test & Indirect effect & $S . E$. & $Z$-value & $p$-value \\
\hline
\end{tabular}

Next, we test model 3 and model 4 to examine the mediating effect of psychological contract. Table 2 summarizes the result of the mediation test for psychological contract. Model 3 is a simple regression between psychological contract and job satisfaction with $R$-square of 0.493 and model significance level $p$-value less than 0.001 . Model 4 is a multiple regression of psychological contract and job satisfaction to job performance. This model returns $R$-square of 0.592 and model significance level $p$ value less than 0.001. Again, the significance of model 3 and 4 allow us to proceed with Sobel test to identify the mediating effect of psychological contract. Sobel test result indicates that the indirect effect of job satisfaction on job performance through psychological contract is 0.221 with significance level $p$-value less than 0.001. It is appropriate to conclude that hypotheses $\mathrm{H} 3, \mathrm{H} 4$ and $\mathrm{H} 6$ are supported.

\section{Conclusions}

\subsection{Conclusions and Discussions}

The theoretical basis of this research came from the earliest job satisfaction. Previous studies found that job satisfaction and job dissatisfaction as two sides of the same coin. Past research for employee satisfaction and behavior tried to find numerous antecedent variables affect employee job performance and the connection of the general work behaviors with dissatisfied working environment empirically. This research is distinct from past organizational citizenship behavior researches, which focused on antecedents or behavior classification. This study attempts to proceed from the angle of the staff when they are dissatisfied with the work situation, particularly the behaviors of employees who perceived different psychological contract of the organizations could adjust or change their behavioral tendencies and even affect their job performance. This study is noteworthy of the use of underlying psychological mechanisms to describe the conceptual framework. Psychological contract and organizational commitment serve as important mediators of the relationship between job satisfaction and job performance.

\subsection{Managerial Implications}

In Human resources management, staff performance will affect the organization's overall performance. Therefore, supervisors should further understand the possible sources in the organizational work environment, which cause job dissatisfaction and thus affect employees' job performance. For staff members, when individuals and organizations formed psychological contract and mutually beneficial relationship because of the employment relationship, employees will have a positive attitude and a positive performance. Obvious effect can be observed whether it is transactional or relational (Rousseau \&Greller, 1994). Practitioners should improve internal relations using the concept of psychological contract and increase the staff continuance commitment and organizational commitment, which results in good job performance under the circumstances of low levels of job satisfaction; if the enterprises were facing inadequate investment of employees, they should strengthen the process and standard of staff selection to improve the quality of the talent needed by the enterprise; or to think about the relationship between business unit in charge of the commitment given to the employees in the form of psychological contract, when the psychological 
contract is violated, employees will have poor job performance or high levels of turnover. Therefore, how to improve the job performance of employees actually put into issues of corporate concern.

\section{REFERENCES}

[1] Allen, N. J., \& Meyer, J. P. (1996). Affective, continuance, and normative commitment to the organization: An examination of construct validity. Journal of Vocation Behavior, 49(3), 252-276.

[2] Ang, S., Van Dyne, L., \& Begley, T. M. (2003). The employment relationships of foreign workers versus local employees: A field study of organizational justice, job satisfaction, performance, OCB. Journal of Organizational Behavior, 24(5), 561-583.

[3] Bakker, A.B., Demerouti, E., \&Sanz-Vergel, A.I. (2014). Burnout and work engagement: The JD-R approach. Annual Review of Organizational and Psychological Organizational Behavior, 1, 389-411.

[4] Becker, H. S. (1960). Notes on the concept of commitment. American Journal of Sociology,66(1), 32-42.

[5] Borman, W. C., \&Motowidlo, S. J. (1993).Personnel Selection in Organizations, San Francisco, CA: Jossey-Bass, Inc.

[6] Brouthers, K. D. (2002). Institutional, Cultural and Transaction Cost Influences on Entry Mode Choice and Performance. Journal ofInternational Business Studies, 33(2), 203-221.

[7] Byars, L. L., \& Rue, L. W. (2000). Human Resource Management.New York, NY: McGraw-Hill, Inc.

[8] Campbell, J. P. (1983). Performance Measurement and Theory.Hillsdale, NJ: Lawrence Erlbaum Associates, Inc.

[9] Campbell, J. P. (1990). Handbook of Industrial andOrganizational Psychology.Palo Alto, CA: Consulting Psychologists Press.

[10] Cascio, W. F. (2006). Managing Human Resources: Productivity, Quality of Work Life Profits.New York, NY: McGraw-Hill, Inc.

[11] Cellucci, A. J., \&DeVries, D. L. (1978). Measuring managerial satisfaction: a manual for the MJSQ. Center for Creative Leadership.

[12] Dawson, G.S., Karahanna, E., \&Buchholtz, A. (2014). A study of psychological contract breach spillover in multiple-agency relationships in consulting professional service firms. Organization Science, 25, 149170.

[13] Dessler, G. (2001). Human Resource Management.Taiwan:Prentice-Hall Int'1.

[14] Farrell, D. (1983). Exit, voice, loyalty, and neglect as responses to job dissatisfaction: A multidimensional scaling study. Academy of Management Journal, 26(4), 596-607.

[15] Ferries, K. R., \&Aranya, N. (1983). A comparison of two organizational commitment scales, Personnel Psychology, 36(1), 87-98.

[16] Granter, E., McCann, L., \& Boyle, M. (2015). Extreme work/normal work: Intensification, storytelling and hypermediation in the (re) construction of 'the New Normal'.

[17] Halbesleben, J. R., Neveu, J. P., Paustian-Underdahl, S. C., \&Westman, M. (2014). Getting to the "COR" understanding the role of resources in conservation of resources theory. Journal of Management, 40(5), 1334-1364.

[18] Hagedoorn, M., Van Yperen, N. W., Van de Vliert, E., \& Buunk, B. P. (1999). Employees' reactions to problematic events: A circumplex structure of five categories of responses, and the role of job satisfaction. Journal of Organizational Behavior, 20(3), 309-321.

[19] Hom, P. W., Caranikas-Walker, F., Prussia, G. E., \&Griffeth, R. W. (1992). A meta-analytic structural equations analysis of a model of employee turnover. Journal of Applied Psychology, 77, 890-909.

[20] Hoppock, R. (1935). Job satisfaction. City, NY: Harper and Row Inc.

[21] Iaffaldano, M. T., \&Muchinsky, P. M. (1985). Job satisfaction and performance: A meta-analysis. Psychological Bulletin, 97, 251-273.

[22] Kreitner, R., \&Kinicki, A. (2001). Organizational Behavior.New York, NY: McGraw-Hill, Inc.

[23] Locke, E. A. (1973). Satisfactions and dissatisfactions among white-collar and blue-collar employee. Journal of Applied Psychology, 58(1), 67-76.

[24] MacNeil, I. R. (1985). Relational contract: What we do and do not know, Wisconsin Law Review, 3(4), 483-525.

[25] March, J., \& Simon, H. (1958). Organizations. New York, NY: Wiley.

[26] Meyer, J. P., \& Allen, N. J. (1991). A three-component conceptualization of organization commitment. Human Resource Management Review, 1(1), 61-89. 
[27] Meyer, J. P., \& Allen, N. J. (1997). Commitment in the workplace: Theory, research, and application.Thousand Oaks, CA: Sage.

[28] Moorhean, G., \& Griffin, R. W. (1998). Organizational Behavior: Managing People and Organizations(8th ed.).New York, NY: Houghton Mifflin Company.

[29] Moorman, R. H. (1991). Relationship between organizational justice and organizational citizenship behaviors: Do fairness perceptions influence employee citizenship? Journal of Applied Psychology, 76(6), 845.

[30] Morris, J. H., \& Sherman, J. D. (1981). Generalizability of and organizational commitment.Academy of Management Journal, 24(3), 512-526.

[31] Morrison, D. E. (1994). Psychological contracts and change.Human Resource Management, 33(3), 353372.

[32] Mowday, R. T., Porter, L. W., \& Steers, R. M. (1982). Employee-organization linkages: The psychology of commitment, absenteeism, and turnover. San Diego, CA: Academic Press.

[33] Mowday, R. T., Porter, L. W., \& Steers, R. M. 1982. Employee-organization linkages. New York, NY: Academic Press.

[34] Organ, D. W. (1988). Organizational citizenship in behavior: The good soldier syndrome. Lexington, MA: Lexintgton Books.

[35] Price, J. L., \& Mueller, C. W. (1981). A Causal model of turnover for nurses. Academy of Management Journal, 24(3), 542-565.

[36] Robinson, S. L., \& Morrison, E. W. (1995). Psychological contracts and OCB: The effect of unfulfilled obligations on civic virtue behavior. Journal of Organizational Behavior, 16(3), 289-298.

[37] Robinson, S. L., Kraatz, M. S., \& Rousseau, D. M. (1994). Changing obligations and the psychological contract: A longitudinal study, Academy of Management Journal, 37(1), 137-152.

[38] Rousseau, D. M.(1989). Psychological and Implied Contracts in Organizations, Employee Responsibilities and Rights Journal, 2(2), 121-139.

[39] Rousseau, D. M., \& Greller, M. M. (1994). Human Resource Practices: Administrative Contract Makers, Human Resource Management, 33(3), 385-401.

[40] Rousseau, D. M., \& Parks, J. M. (1993).The Contracts of Individuals and Organizations. InCummings, L. L., \&Staw, B. M. (Eds.), Research in Organizational Behavior: vol. 15, (pp. 1-43). Greenwich, Conn:JAI Press Inc.

[41] Rusbult, C. E., Zembrodt, I. M., \& Gunn, L. K. (1982). Exit, voice, loyalty, and neglect: Responses to dissatisfaction in romantic involvements. Journal of Personality andSocial Psychology, 43(6), 1230-1242.

[42] Sandral, R., \& Elizabeth W. M. (1995).The Development of Psychological Contract Breach and Violation: A Longitudinal Study, Journal ofOrganizational Behavior, 21(5), 525-546.

[43] Schein, E. H. (1985). Organizational culture and leadership. San Francisco: Jossey Bass.

[44] Seashore, S. E., \& Taber, T. D. (1975). Job satisfaction and their correlation. American Behavior Scientist, 18(3), 333-368.

[45] Smith, P. C., Kendall, L. M., \&Hallin, C. L. (1969). Measurement of satisfaction in work and retirement. Chicago, IL: Read McNally.

[46] Solinger, O. N., Hofmans, J., Bal, P. M., \& Jansen, P. G. (2016). Bouncing back from psychological contract breach: How commitment recovers over time. Journal of Organizational Behavior, 37(4), 494514.

[47] Staw, B. M. (1984). Annual review of psychology. Palo Alto, CA: Annual Reviews.

[48] Steers, R. M., \& Rhodes, S. R. (1978). Major influences on employee attendance: A process model. Journal of Applied Psychology, 63(4), 391-407.

[49] Turnley, W. H., \& Feldman, D. C. (1999). The impact of psychological contract violations on exit, voice, loyalty, and neglect. Human Relations, 52, 895-922.

[50] Van de Vliert, E. (1997). Complex Interpersonal Conflict Behavior: Theoretical Frontiers, Psychology Press, Hove.

[51] Vitell, Scott J., Davis, D. L.(1990). The Relationship Between Ethics and Job Satisfaction: An Empirical Investigation. Journal of Business Ethics, 9(6), 489-494.

[52] Vroom, V. H. (1964). Work and motivation. NY: John Willey and Sons Inc.

[53] Wthey, M. J., \& Cooper, W. H. (1992). What's loyalty? Employee Responsibilities and Rights Journal, 5(3), 231-240.

[54] Wthey, M. J., \&Coopert, W. H. (1989). Predicting exit, voice, loyalty and neglect. Administrative Science Quarterly, 34(4), 521-539. 
[55] Wu, J. B., Hom, P. W., Tetrick, L. E., Shore, L. M., Jia, L., \& Li, C. (2006). The norm of reciprocity: Scale development and validation in the Chinese context. Management and Organization Review, 2(3), 377-402.

[56] Zhou, J., \& George, J.M. (2001). When job dissatisfaction leads to creativity: encouraging the expression of voice. Academy of Management Journal, 44(4), 682-696.

Citation: Cheng-Wei Che, Pei-Ling Tsui, Ming-Chih Chen, Ching-Sung Lee, Yen-Cheng Chen. "Job Performance and Job Satisfaction: Roles of Organizational Commitment and Psychological Contract" International Journal of Research in Tourism and Hospitality (IJRTH), vol 4, no. 1, 2018, pp. 18-26. doi:http://dx.doi.org/10.20431/2455-0043.0401003.

Copyright: (C) 2018 Authors. This is an open-access article distributed under the terms of the Creative Commons Attribution License, which permits unrestricted use, distribution, and reproduction in any medium, provided the original author and source are credited. 